\title{
Strength and Durability Performance of Slag Blended Cements in High Temperature Environments
}

\author{
Ogirigbo, O. R. ${ }^{1, *}$ and Inerhunwa, I. ${ }^{1}$ \\ ${ }^{1}$ Department of Civil Engineering, University of Benin, Benin City, Nigeria \\ Corresponding Author: *okiemute.ogirigbo@uniben.edu
}

\begin{abstract}
In this study, two slags of different chemical compositions were blended with a CEM I 52.5R-type Portland cement at $30 \%$ wt. replacement ratio. Various tests such as strength, water and chloride ion permeability test were carried out at a high temperature of $38^{\circ} \mathrm{C}$. The performances of the slag blends were measured against that of a CEM I 42.5R-type Portland cement. The results obtained showed that the performances of the slag blends were better than that of the CEM I 42.5R cement. In comparing the performances of the slags, the blend prepared from slag 1 had higher strengths and better transport properties than that prepared from slag 2, and this was attributed to the higher basicity and alumina content of slag 1. The findings of the study suggest that in tropical/ high temperature environments, the chemical composition of the slags play an important role in determining their performance.
\end{abstract}

Keywords: Tropical environment, GGBS, Compressive strength, Sorptivity, Chloride ingress

\subsection{Introduction}

Global production of Portland cement is over 4 billion tonnes per year. Consequently, approximately $6 \%$ of anthropogenic $\mathrm{CO}_{2}$ emissions are associated with Portland cement (PC) production (Bye and Livesey, 2011). The drive to reduce this has led to a widespread use of supplementary cementitious materials (SCM) as partial replacement for PC. Ground granulated blast furnace slag (GGBS) is a type of SCM that is obtained as a by-product from the making of iron and steel. The molten iron slag from the blast furnace is quenched with water or steam to produce a glassy and granular material, which is grounded to a fine powder to produce GGBS (Moranville-Regourd, 2003). GGBS has almost the same fineness and specific surface area as PC (Hadj-sadok et al., 2011).

Currently, there is no reliable data regarding the annual production of iron and steel in Nigeria. In a report by (Akinwumi, 2012), it was estimated that about 3.5 to 4.5 million metric tonnes of steel was being produced per annum by the steel plants in Ajaokuta, Delta, Jos, Katsina and Osogbo. In another study by (Ohimain, 2013), it was also stated that about 1.3 million metric tonnes of iron was being produced by the Ajaokuta Steel Company. This implies that more than 0.40 million metric tons of slag could be available annually in Nigeria.

Several studies (Babu and Kumar, 2000; Barnett et al., 2006; Pavía and Condren, 2008; Lothenbach et al., 2011) have shown that using GGBS to partially replace PC in the making of concrete improves its properties. However, most of these studies were carried out in temperate environments. Only few studies, e.g. (Escalante et al., 2001; Ogirigbo and Black, 2016), have looked at how high temperatures affect the performance of slag blends. These studies showed that high temperatures accelerate the early hydration of slags, but the impact this will have on strength and transport properties was not sufficiently investigated. For a tropical environment like Nigeria, where temperatures vary from $26^{\circ} \mathrm{C}$ in the Southern parts to about $45^{\circ} \mathrm{C}$ in the Northern parts, it is imperative to study how high temperatures affect the performance of slag blended cements. 


\subsection{Materials and Methods}

\subsection{Materials}

Two slag blends were prepared by mixing two slags of similar physical properties but different chemical composition (as seen in Table 1), with a CEM I 52.5R-type cement, at a replacement ratio (PC:GGBS) of 70:30. The strength and durability performance of the slag blends were compared against that of a CEM I 42.5R, which is a common type of cement used in Nigeria.

\subsection{Details of Mixes and Curing Conditions}

Three mixes were used for the study - a control mix (C) and two slag mixes designated as S1 and S2 respectively. Mortar samples were prepared from these mixes in accordance with (EN196-1:2005), and were used for all the tests. After mixing, the samples were poured into moulds and left to cure under air for a period of $20-24$ hours. Thereafter, the samples were de-moulded and placed under water in curing tubs maintained at temperatures of $38^{\circ} \mathrm{C}$, which is typical of a tropical environment.

Table 1: Properties of cementitious materials

\begin{tabular}{lcccc}
\hline Property & $\mathrm{S} 1$ & $\mathrm{~S} 2$ & CEM I 52.5R & CEM I 42.5R \\
\hline $\mathrm{CaO}(\%)$ & 38.24 & 37.90 & 62.38 & 63.16 \\
$\mathrm{SiO}_{2}(\%)$ & 36.58 & 40.14 & 19.10 & 19.71 \\
$\mathrm{Al}_{2} \mathrm{O}_{3}(\%)$ & 12.23 & 7.77 & 5.35 & 5.08 \\
$\mathrm{Fe}_{2} \mathrm{O}_{3}(\%)$ & 0.48 & 0.78 & 2.95 & 2.97 \\
$\mathrm{MgO}(\%)$ & 8.55 & 9.51 & 2.37 & 2.19 \\
$\mathrm{Blaine}\left(\mathrm{m}^{2} / \mathrm{kg}\right)$ & 449 & 409 & 571 & 351 \\
$\mathrm{Particle} \mathrm{size}, \mathrm{d} 50(\mu \mathrm{m})$ & 11.0 & 11.9 & - & - \\
Density $\left(\mathrm{kg} / \mathrm{m}^{3}\right)$ & 2940 & 2950 & 3180 & 3230 \\
\hline
\end{tabular}

\subsection{Test Methods}

Unconfined compressive strength (UCS) was determined according to (EN196-1:2005). 40 x $40 \mathrm{x}$ $160 \mathrm{~mm}$ mortar prisms were cast and cured for periods of 1, 7, 28, 90 and 180 days.

Sorptivity was determined in triplicate according to the method used by (Tasdemir, 2003). 50mm mortar samples were used for the test. The samples were cured for 28 days, after which they were dried to constant mass in an oven at $50^{\circ} \mathrm{C}$. After drying, the sides of the samples were coated with paraffin and weighed to obtain the initial mass before they were placed in a trough of water. The water level was kept at about $5 \mathrm{~mm}$ from the base of the samples. The mass of the samples were recorded at predetermined times $(1,4,9,16,25,36,49$ and 64 mins). At each of these times, the mass of water absorbed by each specimen was calculated by subtracting the initial mass from the recorded mass, and from this the sorptivity coefficient $(\mathrm{k})$ was determined using the following expression:

$$
k=Q /(A \sqrt{t})
$$

where:

$Q$ is the amount of water adsorbed in $\mathrm{m}^{3}$

$t$ is the time in seconds

$A$ is the cross-sectional area of the specimen that was in contact with the water in $\mathrm{m}^{2}$

$k$ is the sorptivity coefficient in $\mathrm{m}^{3} / \mathrm{m}^{2} \mathrm{~s}^{1 / 2}$. 
Water absorption tests were carried out according to (BS1881-122:2011) using mortar samples. The mortar samples used were similar to those used for sorptivity test, in that they were prepared and cured in the same way. After curing, the samples were placed in an oven at $105^{\circ} \mathrm{C}$ for a period of $72 \mathrm{hrs}$. Thereafter, the samples were allowed to cool under air for about two hours, after which they were weighed and immersed completely in water for various periods of 10, 30, 60 and 120 mins. The mass of the samples were recorded at each of these times and the water absorbed $\left(W_{a}\right)$ as a percentage was obtained using the expression below.

$$
W_{a}=\frac{K\left(M_{t}-M_{d}\right)}{M_{d}} \times 100
$$

where:
$M_{d} \quad$ dry mass of the sample in grams
$M_{t} \quad$ mass of the sample after time $t$, in grams
$K \quad$ correction factor for the shape of the samples, which is equal to 0.667 (BS1881-
$122: 2011$ )
$W_{a} \quad$ water absorbed in \%

The depth of chloride ion penetration was determined using the silver nitrate colouration technique as used elsewhere (Otsuki et al., 1992; Güneyisi and Mermerdaş, 2007; Ogirigbo and Black, 2017). 50 $\mathrm{mm}$ mortar cubes were exposed to a $3 \% \mathrm{NaCl}$ solution after an initial 28 days of wet curing. The samples were withdrawn periodically at $14,28,56$ and 90 days during the 90 -day soaking period to determine the depths of chloride ion penetration. The withdrawn samples were split in half and the surfaces of the freshly split samples were sprayed with a $0.1 \mathrm{M}$ silver nitrate solution. The presence of free chlorides is indicated by the formation of a white precipitate of silver chloride. Thus, by linear measurements from the edge of the specimen up to the colour change boundary, the depth of free chloride penetration was determined.

\subsection{Results and Discussion}

\subsection{Strength Performance}

Figure 1 shows the unconfined compressive strength (UCS) development of all the mixes at $38^{\circ} \mathrm{C}$. Within the first 28 days, all the mixes had gained more than $85 \%$ of their strength. This can be attributed to the influence of the high temperature curing, which is known to accelerate early hydration of cement, thereby leading to high early strengths (Brooks and Al-kaisi, 1990; Barnett et al., 2006). From the figure, it can be seen that the slag mixes had better strength performance than the plain CEM I 42.5R mix at all ages, unlike other studies at $20^{\circ} \mathrm{C}$ (Ogirigbo and Black, 2015) where early age strength development was found to be retarded with composite cements. The high temperatures here offset this slow strength development. This is because the hydration of slag in the presence of PC depends on the breakdown and dissolution of the glass slag structure by hydroxyl ions released during the hydration of PC (Pal et al., 2003), and this process is known to be accelerated at high temperatures (Escalante et al., 2001). In comparing both slags, the slag 1 mix was expected to perform better than the slag 2 mix due to its higher basicity $(\mathrm{Ca} / \mathrm{Si}=1.05$, as compared to that of slag $2-\mathrm{Ca} / \mathrm{Si}=0.94)$. However, the difference in strength performance between the two slag mixes was only obvious at later ages, of 28 days and beyond. This suggests that in high temperature environments, the basicity of slags which is a function of their chemical composition is an important parameter that can influence their later strength performance. 


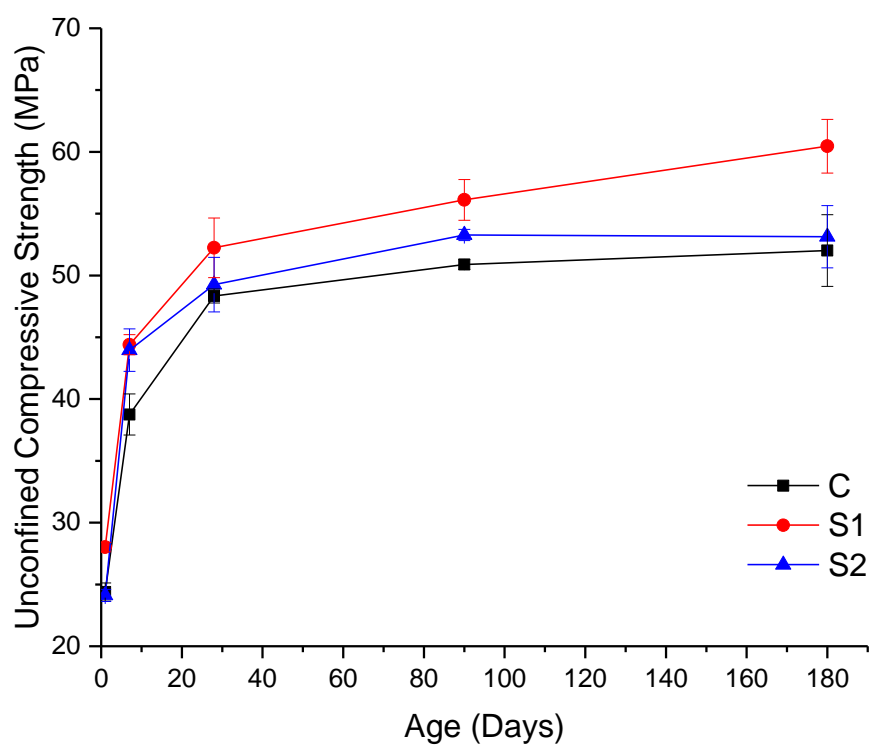

Figure 1: Compressive strength development of all the mixes

\subsection{Durability Performance}

\subsubsection{Water transport}

The 28-day and 90-day sorptivity data are shown in Table 2, while the water absorption curves obtained by plotting the percentage of water absorbed (as determined by Equation 2) against time is shown in Figure 2. Increasing the curing duration from 28 to 90 days resulted in a decrease of about $20 \%$ and $10 \%$ in the sorptivities of the plain CEM I 42.5R mix and the slag mixes respectively. Similar drops were also observed in the water absorption data shown in Figure 2 and Table 3. This shows that prolonged curing improved the resistance to water penetration of all the mixes and agrees with the findings of (Güneyesi and Gesoğlu, 2008).

As observed in the compressive strength results, the slag mixes had better resistance to water penetration than the plain CEM I 42.5R mix. This implies that the pore structure of the slag mixes were more compact and refined than that of the plain cement mix, and explains why the slag mixes had better strength performance than the plain CEM I 42.5R mix.

As also observed in the compressive strength results, the water penetration resistance of the slag $1 \mathrm{mix}$ was better than that of the slag 2 mix. This can also be attributed to the higher basicity of slag 1 , which will enable it to contribute more to the formation of hydration products and to the densification of the pore structure (Ogirigbo and Black, 2016).

Table 2: Sorptivity of all the mixes

\begin{tabular}{lll}
\hline Mix & \multicolumn{2}{l}{ Sorptivity, $\mathbf{k}\left(\mathbf{m}^{3} / \mathbf{m}^{2} \mathbf{s}^{\mathbf{1 / 2}}\right) \mathbf{x} \mathbf{1 0}^{-5}$} \\
\cline { 2 - 3 } & $\mathbf{2 8 ~ d a y s}$ & $\mathbf{9 0}$ days \\
\hline C & $9.9 \pm 0.07$ & $7.7 \pm 0.07$ \\
S1 & $4.0 \pm 0.07$ & $3.6 \pm 0.08$ \\
S2 & $6.3 \pm 0.04$ & $5.6 \pm 0.04$ \\
\hline
\end{tabular}




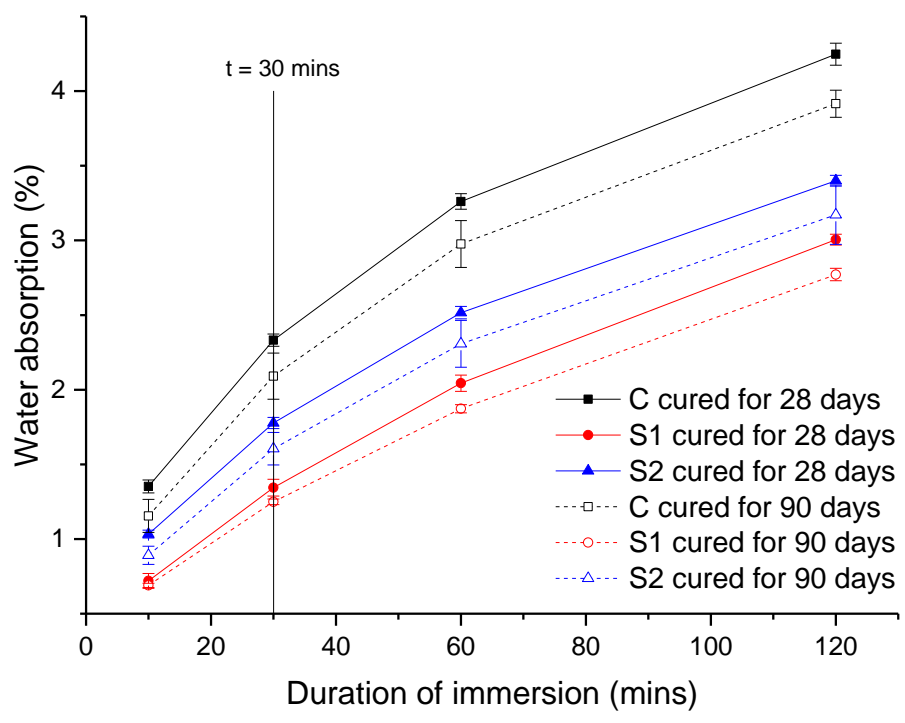

Figure 2: Water absorption curves for all the mixes

Table 3: 30 mins water absorption for all the mixes

\begin{tabular}{lll}
\hline Mix & \multicolumn{2}{l}{ Water absorbed at $\mathbf{3 0} \min (\%)$} \\
\cline { 2 - 3 } & $\mathbf{2 8}$ days & $\mathbf{9 0}$ days \\
\hline $\mathrm{C}$ & $2.3 \pm 0.04$ & $2.1 \pm 0.10$ \\
$\mathrm{~S} 1$ & $1.3 \pm 0.06$ & $1.3 \pm 0.02$ \\
$\mathrm{~S} 2$ & $1.8 \pm 0.04$ & $1.6 \pm 0.11$ \\
\hline
\end{tabular}

\subsubsection{Chloride Ion Transport}

The depth of chloride ion penetration measured for samples which had been cured for 28 days before exposure to a 3\% $\mathrm{NaCl}$ is shown in Figure 3. The slag mixes were seen to have better resistance to chloride ion penetration than the plain CEM I 42.5R mix, especially at 90 days of exposure (see Figure 4). This can be attributed to two factors. The first, being the pore structure, which was seen from the results of the water penetration tests (Table 2 and Figure 2) to be more compact for the slag mixes than for the plain CEM I 42.5R mix. The second, being the chloride binding abilities of the mixes. Several studies (Dhir et al., 1996; Luo et al., 2003; Cheng et al., 2005; Thomas et al., 2012) have shown that slag blended cements have higher chloride binding capacities than plain cements. This implies that the slag mixes bound a greater proportion of the chloride ions that penetrated into the samples, leaving only few chlorides to remain in the pore solution as free chlorides. This high chloride binding ability exhibited by slags have been generally attributed to their higher alumina content (Dhir et al., 1996; Luo et al., 2003; Cheng et al., 2005; Thomas et al., 2012), which in this study (as shown in Table 1) can be seen to be much higher for the slags than for the plain cement.

As also observed in the previous results shown, the slag $1 \mathrm{mix}$ showed better resistance to the penetration of chloride ions as compared to the slag 2 mix. The reason for this can be seen from Table 1 , where the basicity and alumina content of slag 1 was significantly greater than that of slag 2 . 


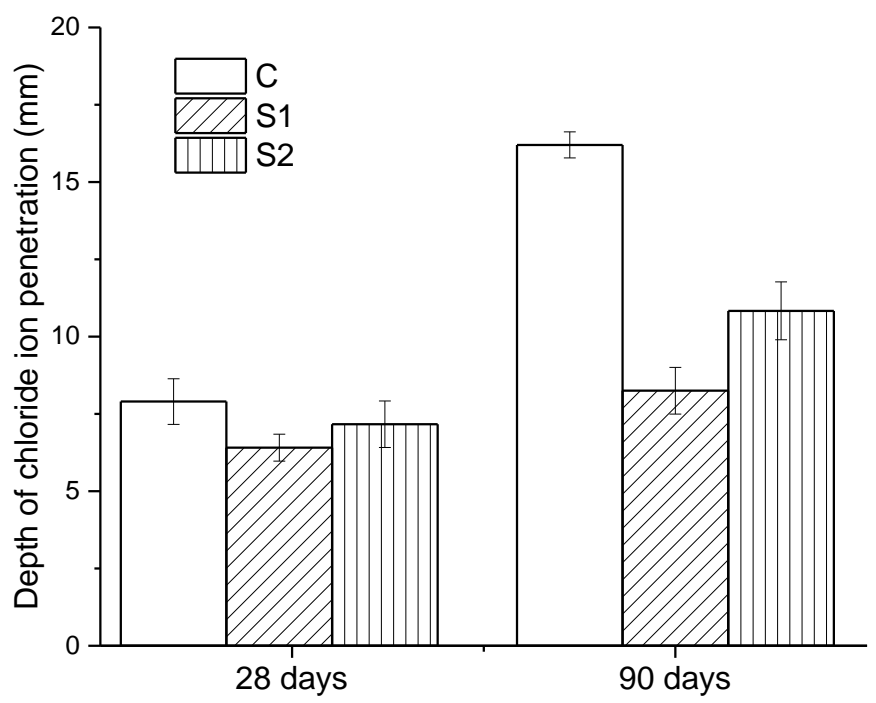

Figure 3: Depth of chloride ion penetration for all mixes after exposure to $3 \% \mathrm{NaCl}$ solution for 28 and 90 days

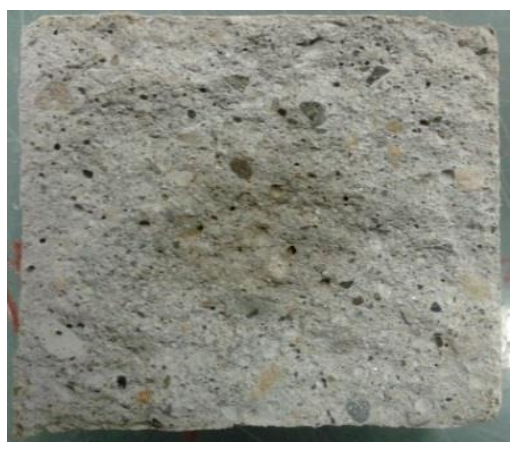

C -28 days wet-cured

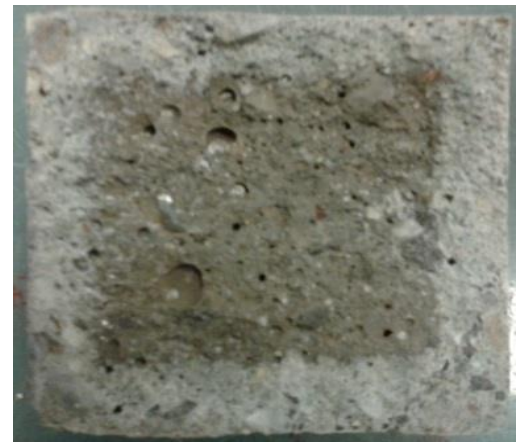

S1 - 28 days wet-cured

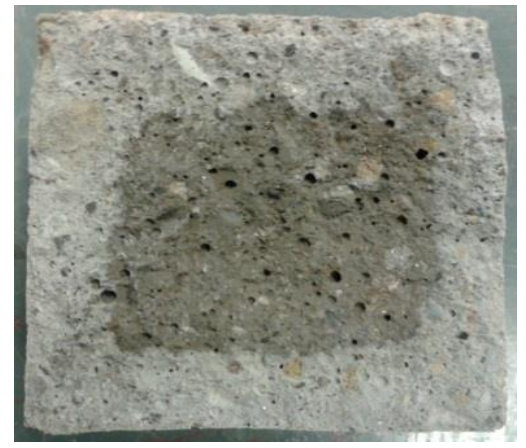

S2 - 28 days wet-cured

Figure 4: Pictures showing extent of chloride ion penetration into mortar samples exposed to a $3 \% \mathrm{NaCl}$ solution for 90 days

\subsection{Conclusions}

This study investigated the strength and durability performance of slag blended cements in high temperature environments. In conclusion, the following points have been highlighted:

- All the mixes had gained more than $85 \%$ of their strength within the first 28 days. This was attributed to the influence of the high temperature curing, which accelerated the early hydration leading to high early strengths.

- The slag mixes had better strength performance than the plain cement mix at all ages. In comparing the strength performance of both slag mixes, slag 1 performed better than slag 2 and this was attributed to its higher basicity.

- For the transport properties studied (water and chloride penetration), the results obtained showed that curing for longer periods enhances the resistance to water penetration. The slag mixes showed better resistance to the penetration of water and chloride ions as compared to the plain cement. This was attributed to the more compact pore structure of the slag blends and their higher alumina contents.

- In comparing both slags, slag 1 showed better transport properties than slag 2 especially in terms of resistance to the penetration of chloride ions. This was attributed to the higher basicity and alumina content of slag 1. 
Overall, the results from this study implies that in hot climates like the tropical regions, slag blended cements have better strength and transport properties than plain cements. Nigeria is fairly rich in slag and is situated in the tropics. Since high temperature enhances the performance of slags, it is recommended that slags are used as partial replacement materials for PC. Also, standards stipulate a minimum $\mathrm{CaO} / \mathrm{SiO}_{2}$ ratio for slags; for example, EN 197-1:2011 prescribes that for GGBS, the $(\mathrm{CaO}+$ $\mathrm{MgO} / \mathrm{SiO}_{2}$ ratio by mass must exceed 1 . The findings of this study show that these ratios would be more important for consideration in tropical environments.

\section{Acknowledgements}

The authors would like to thank Dr Leon Black of the school of Civil Engineering, University of Leeds, for his input in the research study; and also the Petroleum Technology Development Fund (PTDF) Nigeria, for providing the funding for the research work.

\section{References}

Akinwumi, I. I. (2012) Utilization of steel slag for stabilization of a lateritic soil. Masters Thesis, Covenant University, Ota, Ogun State, Nigeria.

Barnett, S. J., Soutsos, M. N., Millard, S. G. and Bungey, J. H. (2006) 'Strength development of mortars containing ground granulated blast-furnace slag: Effect of curing temperature and determination of apparent activation energies', Cement and Concrete Research, 36(3), pp. 434-440.

Brooks, J. J. and Al-kaisi, A. F. (1990) 'Early strength development of Portland and slag cement concretes cured at elevated temperatures', ACI Materials Journal, 87, pp. 503-507.

BS1881-122:2011 'Testing concrete', Method for determination of water absorption. BSI: Brussels.

Bye, G. C. and Livesey, P. (2011) Portland cement. 3rd edn. London: ICE publishing.

Cheng, A., Huang, R., Wu, J. K. and Chen, C. H. (2005) 'Influence of GGBS on durability and corrosion behavior of reinforced concrete', Materials Chemistry and Physics, 93(2-3), pp. 404-411.

Dhir, R. K., El-Mohr, M. A. K. and Dyer, T. D. (1996) 'Chloride binding in GGBS concrete', Cement and Concrete Research, 26(12), pp. 1767-1773.

EN196-1:2005 'Methods of testing cement', Determination of strength. BSI: Brussels.

Escalante, J. I., Gómez, L. Y., Johal, K. K., Mendoza, G., Mancha, H. and Méndez, J. (2001) 'Reactivity of blast-furnace slag in Portland cement blends hydrated under different conditions', Cement and Concrete Research, 31(10), pp. 1403-1409.

Ganesh Babu, K. and Sree Rama Kumar, V. (2000) 'Efficiency of GGBS in concrete', Cement and Concrete Research, 30(7), pp. 1031-1036.

Güneyesi, E. and Gesoğlu, M. (2008) 'A study on durability properties of high-performance concretes incorporating high replacement levels of slag', Materials and Structures, 41(3), pp. 479-493.

Güneyisi, E. and Mermerdaş, K. (2007) 'Comparative study on strength, sorptivity, and chloride ingress characteristics of air-cured and water-cured concretes modified with metakaolin', Materials and Structures, 40(10), pp. 1161-1171.

Hadj-sadok, A., Kenai, S., Courard, L. and Darimont, A. (2011) 'Microstructure and durability of mortars modified with medium active blast furnace slag', Construction and Building Materials, 25(2), pp. 1018-1025.

Lothenbach, B., Scrivener, K. and Hooton, R. D. (2011) 'Supplementary cementitious materials', Cement and Concrete Research, 41(12), pp. 1244-1256. 
Luo, R., Cai, Y., Wang, C. and Huang, X. (2003) 'Study of chloride binding and diffusion in GGBS concrete', Cement and Concrete Research, 33(1), pp. 1-7.

Moranville-Regourd, M. (2003) 'Cements Made from Blastfurnace Slag', in Lea's Chemistry of Cement and Concrete, pp. 637-678.

Ogirigbo, O. R. and Black, L. (2015) 'Influence of slag composition and curing duration on the performance of slag blends in chloride environments', in Yury, V. Z. and Celeste, Z. C. y T. M. (eds) International Conference on Sustainable Structural Concrete. La Plata, Argentina, September 16 - 18, 2015, pp. 110-119.

Ogirigbo, O. R. and Black, L. (2016) 'Influence of slag composition and temperature on the hydration and microstructure of slag blended cements', Construction and Building Materials, 126, pp. 496-507.

Ogirigbo, O. R. and Black, L. (2017) 'Chloride binding and diffusion in slag blends: Influence of slag composition and temperature', Construction and Building Materials, 149, pp. 816-825.

Ohimain, E. I. (2013) 'The Challenge of Domestic Iron and Steel Production in Nigeria', Greener Journal of Business and Management Studies, 3(5), pp. 231-240.

Otsuki, N., Nagataki, S. and Nakashita, K. (1992) 'Evaluation of AgNO3 solution spray method for measurement of chloride penetration into hardened cementitious matrix materials.', ACI Materials Journal, 89(6), pp. 587-592.

Pal, S. C., Mukherjee, A. and Pathak, S. R. (2003) 'Investigation of hydraulic activity of ground granulated blast furnace slag in concrete', Cement and Concrete Research, 33(9), pp. 1481-1486.

Pavía, S. and Condren, E. (2008) 'Study of the Durability of OPC versus GGBS Concrete on Exposure to Silage Effluent', Journal of Materials in Civil Engineering, 20(4), pp. 313-320.

Tasdemir, C. (2003) 'Combined effects of mineral admixtures and curing conditions on the sorptivity coefficient of concrete', Cement and Concrete Research, 33(10), pp. 1637-1642.

Thomas, M. D. A., Hooton, R.D., Scott, A. and Zibara, H. (2012) 'The effect of supplementary cementitious materials on chloride binding in hardened cement paste', Cement and Concrete Research, 42(1), pp. 1-7. 